\title{
Dynamic fragmentation causes low rock-on-rock friction
}

\author{
Tim R. Davies Dept of Geological Sciences, University of Canterbury, Private Bag 4800 Christchurch, \\ New Zealand \\ Mauri J. McSaveney GNS Science, PO Box 30368, Lower Hutt, New Zealand
}

Andrea M. Deganutti IRPI, CNR, Padua, Italy

\begin{abstract}
The low frictional resistance to rock-on-rock sliding reported in large blockslides, in coseismic fault rupture and in laboratory-scale rock friction tests has been attributed to a variety of causes. Herein we propose a mechanical explanation for the reduced friction, which seems likely to be universally relevant to complement other mechanisms. Rock-on-rock sliding of intact brittle rocks always generates a layer of comminuted debris. Rock must fail in order to form and further comminute debris; at local strain rates $>100 \mathrm{~s}^{-1}$, recycling of elastic strain energy stored in accomplishing fragmentation generates instantaneous, local, GPa-range isotropic pressures similar to the rock's Hugoniot elastic limit (Q). Under rapid strain, simultaneously fragmenting grains deliver large normal forces to the boundaries of the comminuting layer, reducing the confining stress on the debris (and hence its resistance to shear), thus lowering the frictional resistance to slip. This behaviour corresponds quantitatively to published laboratory data on granite friction; to the dynamics of low-angle blocksliding and faulting; and to our data on rapid shearing of fragmenting dry coal.
\end{abstract}

\section{INTRODUCTION}

Anomalously low frictional resistance to the motion of rock masses has been reported or inferred from time to time in a number of geological situations. Lower-than-normal resistance to rock-onrock slip is widely inferred in fault motion (e.g. Scholz, 2002; Parsons, 2002; Townend and Zoback, 2004), which involves shear in comminuted rock debris. Rapid, low-angle motion of large intact blockslides generates comminuted material at the sliding surface (Anders et al, 2000) and unequivocally requires low basal friction (Davies et al, 2006). Reduced slip resistance is also reported in laboratory-scale rock-on-rock sliding (Kilgore et al, 1993; Byerlee, 1978; Di Toro et al, 2004; Goldsby and Tullis, 2002).

Explanations of these phenomena have focussed on particular environments. For example, Di Toro et al (2004) attribute their dramatically low friction data to formation of weak silica gel in the presence of moisture on the laboratory rock surface, which is difficult to apply to the much larger-scale situation of blocksliding. Reduced resistance to slip in faulting is often explained (Lachenbruch, 1980; Sibson, 1994) with high-pressure pore water, which likewise cannot apply to the laboratory result.

Herein we explore a mechanism capable of reducing slip resistance in these situations; the intense local pressure generated by dynamic failure of brittle rock reduces frictional resistance to motion by reducing the effective stress between the sliding surfaces, under a normal coefficient of friction.

\section{DYNAMIC ROCK FRAGMENTATION}

\subsection{General description}

In brittle rock sliding, wear of the sliding surfaces always occurs (Scholz, 2002); rock fragments accumulate between the sliding surfaces and further comminute, forming a debris layer. Rapid breakage of intact (i.e. unjointed) rock - ("dynamic fragmentation": Grady and Kipp (1987) - requires that the rock is stressed beyond its dynamic (or Hugoniot) elastic limit $(\mathrm{Q}$ - the temperature-, strain-rate- and confinement-stress-related value of the compressive strength). When a particle deforms rapidly in a shear field, its internal elastic-strain energy increases; this energy is extracted locally from the surrounding kinetic energy field. The stress state of the deforming particle rapidly approaches, and then exceeds, its strength. It suddenly fails, breaking on newly-generated fracture surfaces defining smaller sub-fragments (Sagy et al, 2001; Zhang et al, 2000, 2004). 


\subsection{Energy transformations in fragmentation}

As an intact clast subjected to compressional and confining stresses initially deforms elastically, the internal stress approaches the elastic limit Q of the intact rock material; this is a function of strain rate and confining stress. Immediately before $Q$ is reached (somewhere in the clast), the elastic strain energy stored by the clast is $\mathrm{SE}_{1}$. When $\mathrm{Q}$ is exceeded somewhere in the clast, a set of cracks appears defining a set of sub-clasts $a_{1}, a_{2}, a_{n}$.

Development of a crack requires inter-molecular bonds to be broken; by definition this takes place at the stress Q, which is the areally-averaged strength of the bonds. The genesis of the crack is the crack walls moving apart by a perpendicular distance $\delta y$, so the work done in generating the crack $=\mathrm{Q} \delta \mathrm{y}$. This is exactly the same as the work that would be done in further straining the clast by $\delta y$ in the $a b-$ sence of crack development, because it is done at the same stress. The total work done to cause failure of the clast from a previously-defined state is exactly the work done in straining it from that previous stress state.

Momentarily, each subclast has almost the same shape as their corresponding mass had prior to cracking; some energy is transformed to noise and heat during the creation of the cracks, so the elastic strain energy is reduced somewhat. Hence $\mathrm{SE}_{1} \sim$ $\Sigma \mathrm{SE}_{\mathrm{a}}$; the elastic strain energy stored in the mass is only slightly reduced by crack appearance.

Once through-going cracks exist, subclasts can move relative to each other under the applied stress field. Instantly, much remaining elastic strain energy converts to kinetic energy. The total released elastic strain energy is close to $\mathrm{Q}^{2} / 2 \mathrm{E}$ per unit volume (Herget, 1960). Displacement of clasts generates frictional resistance to relative subclast motion,

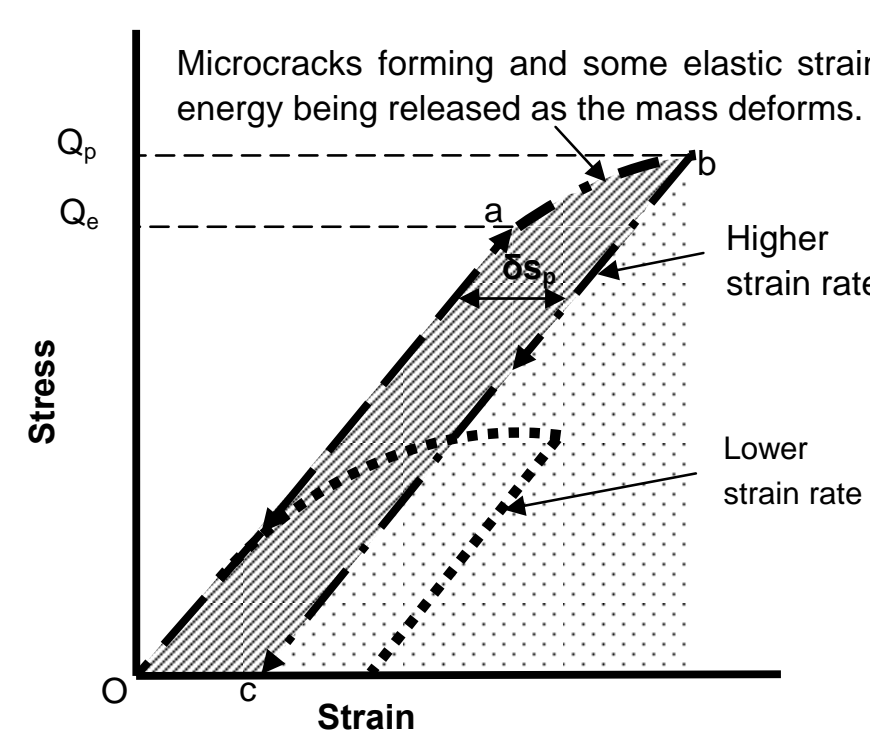

Fig. 1 Stress-strain curve for failing solid dissipating some of the kinetic energy. The above is still valid if the cracks develop progressively through the clast from the point of initial failure; in this case kinetic energy is generated locally as failure progresses through the clast. The strain rate needed to cause dynamic fragmentation is $\sim 100 \mathrm{~s}^{-1}$ (Melosh et al, 1992). At strain rates $\left(>100 \mathrm{~s}^{-1}\right)$ of interest, the kinetic energy is effectively available throughout the clast immediately; Li et al (2005) show that duration of fragmentation of a $70 \mathrm{~mm}$ granite clast is of the order of $100 \mu \mathrm{s}$ at strain rates of $20-60 \mathrm{~s}^{-1}$.

This process can be represented by Fig. 1. The initial strain of the clast is linear $(\mathrm{O}-\mathrm{a})$; prior to failure, in general, some plastic strain occurs in the curved path between $b$ and $c$, the extent of which is determined by the material properties and strain rate. In the case of a brittle solid strained rapidly, the difference between the elastic limit $Q_{e}$ and the ultimate or plastic limit $\mathrm{Q}_{\mathrm{p}}$ will be very small. The total work done in stressing the clast to failure is the sum of the dotted and shaded areas in Fig. A. The release of elastic strain energy on failure causes the curve to fall along b-c, and the energy thus released is that of the dotted area. In the case of brittle failure under rapid strain, the plastic strain $\delta s_{p}$ is very small, and the energy dissipated during failure - the shaded area - is also small. Hence most of the work done in brittle failure of a clast is transformed into kinetic energy of the sub-clasts. This is the "explosive fragmentation" reported by Wawersik and Fairhurst (1971) and Li et al (2005).

Note that the energy expended is the work done in deforming the rock mass; it is not expended in breaking the rock and is not associated with the newly created fragment surfaces. Note also that in the above the only elasticity involved is that of the clast. The elasticity of the environment applying the stress is unspecified; in effect it is subsumed into Q. a laboratory situation is caused entirely by the elasticity of the testing machine, but this is clearly untrue; machine elasticity has some influence, but in principle the machine could have the same elasticity as the clast - deep-mine rockbursts are exactly this case, as are dynamic fragmentations in shearing granular rock masses. The only situation in which brittle fragmentation is not explosive is in a servocontrolled testing machine that reduces stress as soon as strain occurs - which is in effect operating the machine with negative elasticity numerically equal to that of the clast so that the total elasticity is always zero (Hazzard et al, 2000, Fig 12). This situation does not occur in nature.

The elastic-strain energy released at failure thus converts mostly to kinetic energy of sub-fragments moving away from the original centre of mass at ve- 
locities $>10 \mathrm{~ms}^{-1}$ for common rock types (Herget, 1988; Bergstrom, 1963), with some loss to heat in the imperfectly elastic strain and release processes. The sum of fragment momenta with respect to the original particle centre of mass is zero. In tightlypacked debris, the travel distance of the highvelocity sub-fragments is very small, and their effect on the surroundings is that of a short-lived local dispersive pressure.

\subsection{Effects of dynamic fragmentation}

Crack propagation in rapid failure of brittle rock takes place as high-speed (typically $\sim \mathrm{km} \mathrm{s}^{-1}$ ) expansion of a "failure front" through the particle (Espinoza and $\mathrm{Xu}, 1997$ ). The shear strength of the fragmenting material is very low (e.g. Benz and Ausphaug, 1995), hence the resulting dispersive pressure is isotropic. Since the pressure in the vicinity of the failure front is slightly above Q (Espinoza and $\mathrm{Xu}, 1997$; Reches and Dewers, 2005), the magnitude of the dispersive pressure on the surrounding grains is similar to Q. Q for crustal rocks at high shear rates is $\sim 2$ - $4 \mathrm{GPa}$ (Sharpton et al, 1996), so instantaneous local isotropic dispersive pressures of this order result from rapid compressive grain failure (Reches and Dewers, 2005).

A single layer of fragments sheared and comminuted between two rock surfaces delivers this dispersive pressure directly to the surfaces, opposing the external confining stress. This is likely to be the situation early in a rock-on-rock friction experiment, or a rupture in re-agglomerated fault gouge, or a first-time blockslide; very large local forces are applied to the intact rock surfaces by fragmenting grains, reducing the effective stress on the fragment layer and thus reducing the frictional resistance to motion that the layer can develop with a friction coefficient in the usual range 0.5-0.7. As shearing and fragmentation continue, the single layer of fragments develops into a granular mass comprising many layers of smaller fragments (Fig. 2); while new large fragments are introduced by continued failure of the intact boundaries.

\section{GRAIN FLOW}

\subsection{Shear localisation}

Shear bands, indicating localisation of shear strain and comprised of fine, highly-comminuted debris, are frequently reported from fault motion (Sibson, 2003) and blockslides (Anders et al, 2000). Laboratory experiments show that shear localisation occurs preferentially under high confining stresses in association with comminution (Aharonov and Sparks, 2006; Mair et al, 2002), and that the inclination of the shear band to the direction of shear reduces from $\sim 12^{\circ}-20^{\circ}$ to a very low value as the rate of strain increases (Morrow and Byerlee, 1989).

Shear bands reported in non-fragmenting granular materials are $\sim 10$ grain diameters deep (François et al, 2002); frictional resistance within such bands is somewhat lower than in deeper layers Siavoshi et al, 2006).

If confining pressures are significant, the shear rate in the shear band may become sufficient to cause grain fragmentation to occur as a result of compressive stress in a grain bridge (see below). Where a new failure surface is generated, as in initiation of a fault rupture in intact or rewelded rock, or of a first-time blockslide, the debris at the failure surface will initially be about the same size as the gap between the bounding intact rock surfaces; this will however rapidly comminute, and when the ratio of debris thickness to grain diameter exceeds 10, shear localisation will begin to occur (Fig. 2). Shear banding has the effect of substantially increasing the local strain rate.

\subsection{Grain bridges and fragmentation}

Shearing of a non-fragmenting grain mass is dominated by stresses in short-lived, quasi-linear grain columns brought into compressive contact by shear strain. These have been called force chains or grain bridges (Anthony and Marone, 2005). Forming in the direction of maximum local compressive strain, grain bridges transmit normal and resisting stresses between the boundaries; the many grains not instantaneously part of a bridge carry lower stresses than those in bridges. Continued shearing of the grain mass steepens and thus shortens the bridges, increasing their intergranular compressive stress. In three dimensional, widely graded debris
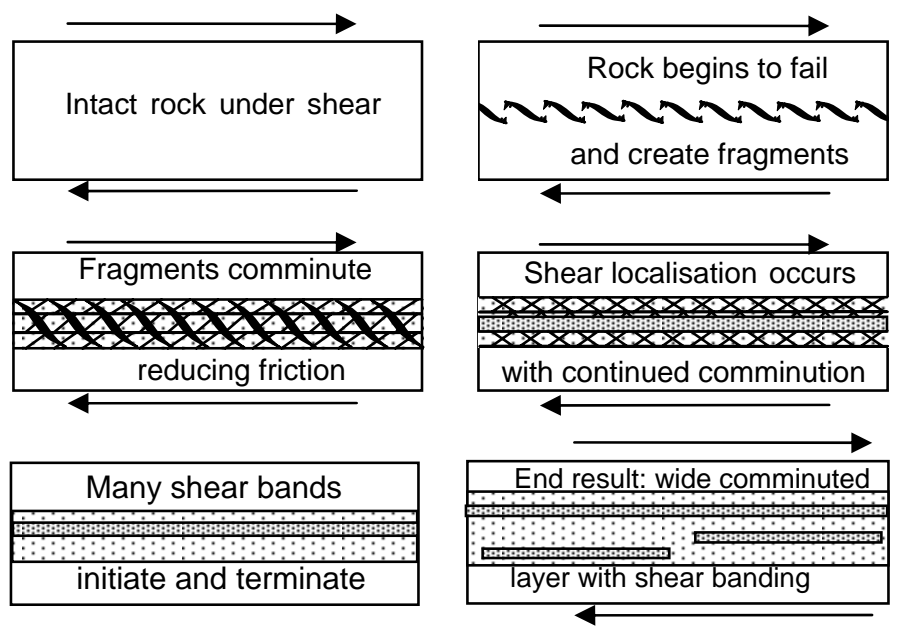

Fig. 2 Development of shear localization in com3 minution on a new failure surface 
with irregularly-shaped particles (Hazzard and Mair, 2003), the bridges are possibly somewhat diffuse and irregular, nevertheless they retain their function. Grain bridges can fail and become shorter by buckling, or by grain fragmentation under compressive stress; when the latter happens the failed bridge shortens immediately, transferring stress to adjacent grains which immediately form other bridges.

Once assembled, a grain bridge in a shear field is advected so that its inclination to the shear direction increases; this causes it to shorten, and the compressive stresses in it increase rapidly (at a rate dependent on the end conditions). At the same time the shear stress tending to cause grain slip increases as the inclination of the bridge increases, but much more slowly than the increase in compressive stress, for rock of normal elasticity. Advection therefore rapidly increases the available frictional resistance to intergranular sliding or slip. Hence, once a bridge is assembled with compressive stresses between all grains, failure by slipping is unlikely. This conclusion corresponds to the observation in twodimensional computer simulations of shearing, that bridge failure by slip is rare (Kuhn, 1999). In a natural shear zone with highly non-spherical comminuted grains, the possibility of failure by grain rolling is also slight.

The most likely grain-bridge failure mode is therefore that of buckling (King \& Sammis, 1992). Confining pressure of surrounding material significantly increases the ability of the column to resist buckling failure (Toakley, 1965; Battacharya et al, 2004). A grain bridge in a low confining pressure is thus able to fail by buckling before the compressive strength of a constituent grain is reached. With higher confining pressure, it is more likely that bridge failure will occur by grain crushing. This corresponds to the common observation of a surface "carapace" of less-fragmented rock above the pervasively-fragmented interior of many large rock avalanche deposits (e.g. Dunning, 2004), and indicates that the confining pressure needed to cause fragmentation is that at the base of the carapace.

Assessment of the confining pressure causing grain bridges to fail by crushing rather than buckling is presently beyond our capability: details of bridge geometry and end conditions affect any calculation, and appear unknowable; and the passive resistance able to be mobilised by the surrounding fractally-graded granular material, and the strain needed to mobilise it, are also imponderables.

Grain bridges must span the width of an active shear zone, and shear bands are usually $\sim 10$ grains wide (François et al, 2002), hence grain bridges are $\sim 15$ grains long. Both grain and bridge strengths increase with shear rate (Biegel et al, 1989; Marone and Kilgore, 1993). These considerations suggest that stronger bridges more likely to fail by fragmentation occur:

1. in the shear zones associated with shear localisation at high shear rates, which are required for dynamic grain fragmentation, and are also typical of fault rupture and blocksliding; and

2. under high confining stresses.

\subsection{Effects of fragmentation stresses}

A fragmenting grain loses most of its shear strength (e.g. Benz and Ausphaug, 1995), so little frictional resistance to slip can be transferred between the boundaries through a failing bridge. The effect of this on frictional resistance can be demonstrated by considering a gouge comprising comminuting grains with $\mathrm{Q}=1 \mathrm{GPa}$ and applied normal stress of $100 \mathrm{MPa}$; a single grain fragmenting simultaneously in each of as few as $2 \%$ of grain bridges reduces the effective normal stress on the debris by $2 \%$ of $\sim 1 \mathrm{GPa}$ to $\sim 80 \mathrm{MPa}$, and the frictional resistance to $\sim 80 \%$ of its non-fragmenting value, assuming conventional friction in the shearing grain mass. The reduced frictional resistance to relative motion of the rock boundaries is partly offset by energy abstracted from the boundary motion to cause fragmentations (Bergstrom, 1963); however this is a small proportion of the total frictional energy dissipation, and so does not greatly affect friction (Tarantino and Hyde, 2005).

\subsection{Fragmentation stress in a shear band}

Consider a thin granular, shearing fragmenting stratum between a deep moving non-fragmenting layer and a stationary base (Fig. 3): in which $\mathrm{P}_{\mathrm{OB}}$ is the overburden pressure at top of the fragmenting layer, $\mathrm{P}_{\mathrm{F}}$ is the average fragmentation pressure in the fragmenting layer and $\mathrm{P}_{\mathrm{E}}$ is the effective intergranular direct stress in the fragmenting layer. All stresses are assumed time-invariant, as is strain rate.

Applying a vertical stress balance at the top of the fragmenting layer:

$\mathrm{P}_{\mathrm{E}}=\mathrm{P}_{\mathrm{OB}}-\mathrm{P}_{\mathrm{F}}$

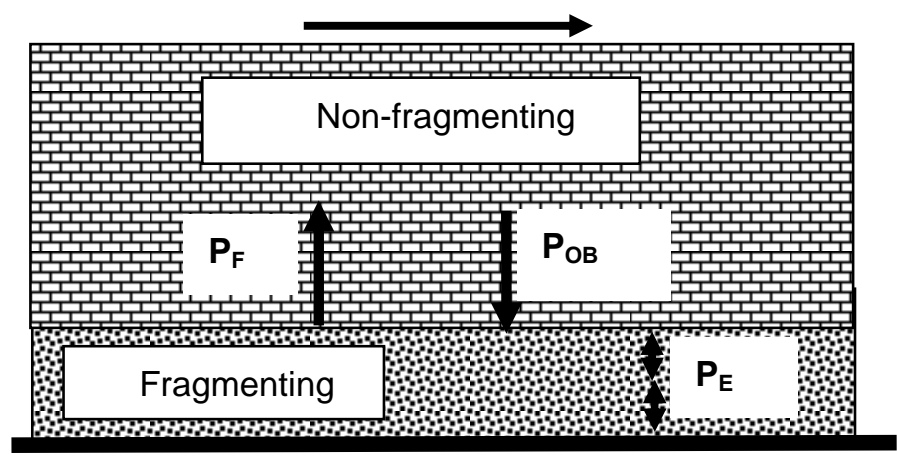

Fig. 3 Diagram for derivation of $\mathrm{P}_{\mathrm{E}}$ 
Each fragmenting grain generates a pressure $=\mathrm{Q}$, so

$\mathrm{P}_{\mathrm{F}}=\mathrm{k}_{1} \mathrm{~F}_{\mathrm{f}}$

where $F_{f}=$ proportion of grains fragmenting simultaneously; $\mathrm{k}_{1}=\mathrm{Q} \sim 10^{9} \mathrm{~Pa}$.

It seems reasonable to expect that the proportion of grains fragmenting simultaneously (at a given shear rate) will depend on the amount by which the effective intergranular direct stress $\mathrm{P}_{\mathrm{E}}$ exceeds the minimum value needed to cause fragmentation $\mathrm{P}_{\mathrm{C}}$ :

$\mathrm{F}_{\mathrm{f}}=\mathrm{k}_{2}\left(\mathrm{P}_{\mathrm{E}}-\mathrm{P}_{\mathrm{C}}\right)$

assuming the dependency is linear.

In the Falling Mountain simulation (Davies \& McSaveney, 2002), fragmentation occupied $>80 \%$ of the (unconfined) flow depth and no shear banding was apparent. The mean fragmentation stress explaining runout distance was $\sim 2.5 \mathrm{MPa}$, which required $\mathrm{F}_{\mathrm{f}} \sim 0.01$. The mean overburden pressure resulting in this stress was $\sim 0.75 \mathrm{MPa}$. The minimum stress required to cause fragmentation $\left(\mathrm{P}_{\mathrm{C}}\right)$ was that at the base of a relatively unfragmented carapace, $\sim 0.3 \mathrm{MPa}$, or $10^{-3}$ times the ambient $\mathrm{Q}$.

Applying these empirical data to (3), $0.01=\mathrm{k}_{2} \mathrm{X}$ $0.45 \times 10^{6}$ and $\mathrm{k}_{2}=2 \times 10^{-8}$.

From (1), (2) \& (3),

$\mathrm{P}_{\mathrm{F}}=\mathrm{k}_{1} \mathrm{k}_{2}\left(\mathrm{P}_{\mathrm{OB}}-\mathrm{P}_{\mathrm{C}}\right) /\left(1+\mathrm{k}_{1} \mathrm{k}_{2}\right)$

$$
\mathrm{k}_{1} \mathrm{k}_{2}=10^{9} \times 2 \times 10^{-8}=20 \text { so }
$$

$\mathrm{P}_{\mathrm{F}}=20\left(\mathrm{P}_{\mathrm{OB}}-\mathrm{P}_{\mathrm{C}}\right) / 21=0.95\left(\mathrm{P}_{\mathrm{OB}}-\mathrm{P}_{\mathrm{C}}\right)$

Hence

$\mathrm{P}_{\mathrm{E}}=\mathrm{P}_{\mathrm{OB}}-\mathrm{P}_{\mathrm{F}}=0.05 \mathrm{P}_{\mathrm{OB}}+0.95 \mathrm{P}_{\mathrm{C}}$

Thus any rock shear whose motion is dominated by a fragmenting layer will experience a frictional resistance to motion $\left(\mu \times \mathrm{P}_{\mathrm{E}}\right)$ of the order of that given by (6).

\section{APPLICATIONS}

\subsection{Blockslides - Waikaremoana and Heart Mountain}

We have modelled the dynamics of the Waikaremoana blockslide in New Zealand (Davies et al, 2006). About 2200 years ago this $1.4 \mathrm{~km}^{3}$ intact sandstone block slid $\sim 2 \mathrm{~km}$ on a basal slope of the same rock inclined at $\sim 7^{\circ}$, accelerating from rest to about $40 \mathrm{~ms}^{-1}$. A $\sim 300 \mathrm{~mm}$ deep stratum of fine sand-sized rock debris has been found in the loca- tion of the inferred sliding surface, suggesting an overall shear rate $\sim 130 \mathrm{~s}^{-1}$ (but clearly much higher in narrow shear bands); such strata are common in large low-angle blockslides (Anders et al, 2000). Geostatic stress due to the weight of the 275-m deep block is about $6.6 \mathrm{MPa}$, and the value of $\mathrm{Q}$ at the ambient conditions is of the order of $0.2 \mathrm{GPa}$. Applying (6) to this situation, the frictional retarding stress in shear bands should be $\sim 0.05 \times 6.6+.95 \times$ $0.2=0.52 \mathrm{MPa}$. The net downslope stress (gravity component minus friction) is then $6.6 \sin 7^{\circ}-0.52=$ $0.28 \mathrm{MPa}$. Since the mass of the block per unit base area is $0.69 \mathrm{ktm}^{-2}$, this stress would cause the intact block to accelerate at $0.4 \mathrm{~ms}^{-2}$. Two kilometres of travel at this acceleration would develop a velocity of about $40 \mathrm{~m} / \mathrm{s}$, which is close to that suggested independently by Davies, et al. (2006) on the basis of physical modelling.

The $\sim 3500 \mathrm{~km}^{3}$ Heart Mountain blockslide in Wyoming/Montana, USA had an intial thickness of several $\mathrm{km}$, and travelled $45 \mathrm{~km}$ on a basal slope of $\sim 2^{\circ}$ (e.g. Beutner \& Gerbi, 2006). The mechanics of its low-friction travel have remained a puzzle for over half a century. If we apply Eq. (6) to the situation, assuming normal rock density, $\mathrm{Q}=1 \mathrm{GPa}$ and $\mathrm{P}_{\mathrm{C}}=1 \mathrm{MPa}$, we find that the basal friction angle $\left(\tan ^{-1}\left(\mu \mathrm{P}_{\mathrm{E}} / \mathrm{P}_{\mathrm{OB}}\right)\right)=1.8^{\circ}$, indicating that basal layer fragmentation can allow the block to accelerate on a basal slope of $2^{\circ}$.

\subsection{Fault rupture}

Low apparent friction coefficients $\left(\mu_{\mathrm{a}}=0.1-\right.$ 0.3 ) are often inferred in the motion of large strikeslip faults (e.g. Freed and Lin, 2002; Townend and Zoback, 2004). Townend \& Zoback (2004) infer that the San Andreas fault ruptures locally with a friction coefficient as low as 0.06. Along the San Francisco peninsula, for example, the direct shear stress at rupture is $\sim 180 \mathrm{MPa}$, while the shear stress is $\sim 10 \mathrm{MPa}$. If we apply Eq. (6) to rupture at $15-\mathrm{km}$ depth, with a confining stress of $400 \mathrm{MPa}$ and $\mathrm{Q}=$ $1 \mathrm{GPa}$ we obtain $\mathrm{P}_{\mathrm{E}} \sim 20 \mathrm{MPa}$ and the resisting stress is $\sim 0.6 \times 20=12 \mathrm{MPa}$; close to the stress needed to rupture the San Andreas fault (Townend \& Zoback, 2004).

\subsection{Laboratory data}

In a laboratory experiment measuring rock-onrock friction of Arkansas novaculite (a very hard metasedimentary quartz rock), Di Toro et al (2004) found frictional resistance reduced to about $30 \%$ of normal at high shear rates $\left(\sim 100 \mathrm{~s}^{-1}\right)$ and normal stresses of $5 \mathrm{MPa}$, accompanied by extrusion of rock gouge. They tentatively attribute the reduced friction to development of a silica-gel layer. We ex 
plain it differently - the gouge-forming rock fragmentation developed dispersive pressure, reducing the effective normal stress on the sliding surfaces. If we apply Eq (6), assuming Q $\sim 1 \mathrm{GPa}$ at the quoted shear rate gives $\mathrm{P}_{\mathrm{c}}=1 \mathrm{MPa}$, and $\mathrm{P}_{\mathrm{E}}=5 / 20+1=$ $1.25 \mathrm{MPa}$. If $\mu=0.6, \mathrm{P}_{\mathrm{f}}$ is $0.75 \mathrm{MPa}$ and the apparent friction coefficient is $0.75 / 5=0.15$, compared with their quoted 0.2 .

That dynamic fragmentation is needed to significantly lower friction is indicated by the fact that only very minor friction variations from normal are reported at shear rates $<<1 \mathrm{~s}^{-1}$, even at high normal stress (Kilgore et al, 1993; Byerlee, 1978; Mair et al, 2001; Beeler et al, 1996).

\subsection{Rheometer tests}

We have used a $300 \mathrm{~mm}$ diameter cone-and-plate rheometer (Davies et al, 2005) to measure the stresses generated by shearing $\sim 1$ litre of dry granular coal at strain rates $\sim 50 \mathrm{~s}^{-1}$ and confining pressures up to $0.3 \mathrm{MPa}$, sufficient to cause pervasive grain fragmentation. Coal is a weak, brittle material with $\mathrm{Q} \sim 10 \mathrm{MPa}$ and crushing behaviour characteristics similar to those of quartz (Charles, 1957). With grains of chosen size in the sample space, the sample bowl was rotated at a chosen rate and a chosen direct stress applied. Typical output data are shown in Fig. 5; using 4-8 mm grains, friction was initially very low and increased with strain as grains comminuted by fragmentation. At the conclusion of the test (total strain 400) the sample was intensely comminuted, particularly against the roof, and because of the lack of new material being supplied the voids ratio of the sample became very small and comminution ceased. The behaviour shown in Fig. 5 requires a reduction of about $15 \%$ (or $0.04 \mathrm{MPa}$ ) in the normal stress on the sample; this would be provided by coal grains fragmenting simultaneously in about $1 / 500$ grain bridges, or $1 / 5000$ grains. If we apply Eq (6), assuming $\mathrm{P}_{\mathrm{C}}=10^{-3} \mathrm{x} \mathrm{Q}=10 \mathrm{kPa}$, then $\mathrm{P}_{\mathrm{E}}=0.05 \times 125+0.95 \times 10=15.75 \mathrm{kPa}$, compared with the measured $12.5 \mathrm{kPa}$.

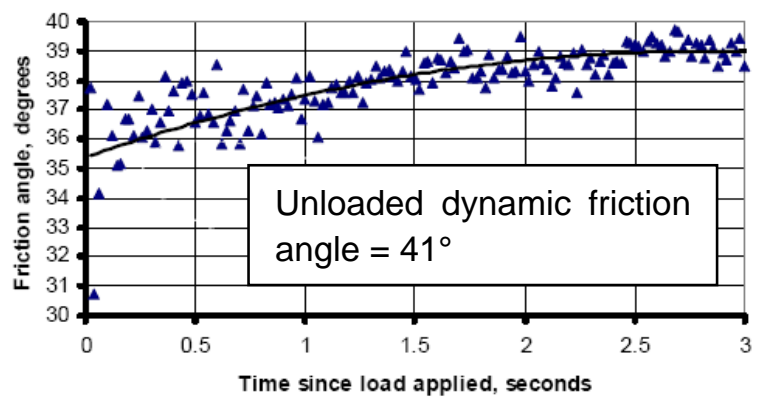

Fig. 5 Rheometer test (raw data) from fragmenting coal granules (4-8 $\mathrm{mm}$ sieve fraction) shearing under $250 \mathrm{kPa}$ normal load. Shear rate $\sim 50 \mathrm{~s}^{-1}$.

\section{RATE OF COMMINUTION}

Continuing re-fragmentation of grains causes an increasingly rapid reduction in grain-size with time; but it cannot cause grain-size to reduce to zero. In the situations considered above, new fragments are recruited from the rock boundaries of the shearing debris when shear bands are adjacent to them, offsetting to some extent the net reduction in average grain-size. Initial fragment sizes (Grady and Kipp, 1987; Zhang and Hao, 2003) of $\sim 10-100 \mathrm{~mm}$ have been noted at strain rates $\sim 100 \mathrm{~s}^{-1}$. Further complications arise from the wide range of fragment sizes and fragment numbers resulting from individual fragmentations. However, order-ofmagnitude spreadsheet simulations using average conditions and uniform time-varying grain size (for example, that for comminution in a deep fault rupture with confining stress $\sim 200 \mathrm{GPa}$ is illustrated in Fig. 6) suggest that with realistically-sized initial fragments, fragmentation pressures in the GPa range, shear localisation with $\sim 10$ grains per bridge, and fresh fragments being recruited, a fragmenting shear band can persist long enough for fault motion to be realistic without creating zerosized gouge. A similar exercise for block sliding reaches the same conclusion.

\section{COMMENTS}

The mechanism we propose is based on the stresses known to be associated with and generated by dynamic rock fracture, and requires only conventional friction coefficients; it also requires that a significant proportion of the strain energy applied to fragmentation is recovered as kinetic energy of the fragments. The latter requirement is met in reality.

While the kinematics and dynamics of threedimensional fragmenting grain flows comprising widely-graded, angular grains are as yet poorly

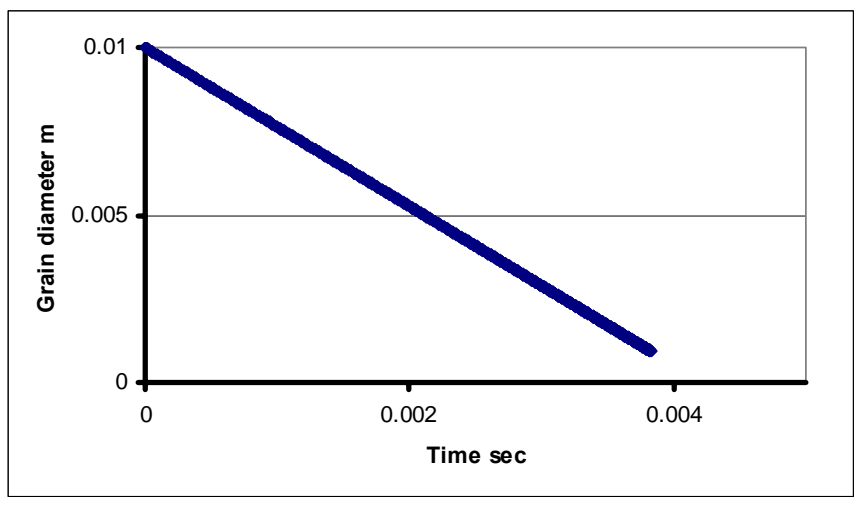

Fig. 6 Comminution of $10 \mathrm{~mm}$ grains in a shear band under fault rupture conditions; duration of shear band $\sim 1 / 250 \mathrm{sec}$. Low-friction fault motion of $0.1 \mathrm{sec}$ requires 25 shear bands to act sequentially. 
known (and difficult to study with real materials), the behaviour of simpler granular flows is compatible with the proposed mechanism by allowing transfer of stresses from fragmenting grains through grain bridges to the boundaries of the shear bands in which most of the motion is taking place.

\section{CONCLUSIONS}

Rapid fragmentation of intact rock under high confining stress generates dispersive pressures of the order of GPa on the surrounding rocks. These pressures result from recovery of much of the strain energy developed in rock failure, in the form of kinetic energy. Fragmentation in a thin band of localised shear opposes the confining stress and reduces the effective stress in the shear band, correspondingly reducing the available frictional resistance to shear. The residual frictional resistance is approximated by Eq. (6); it quantitatively explains the motion of the Waikaremoana and Heart Mountain blockslides. This mechanism also successfully explains the reduced friction inferred in coseismic fault rupture and measured in laboratory rock-onrock friction tests. The ability of fragmentationderived pressure to explain reduced frictional resistance to rock sliding hitherto seems likely to be significant either as a complement to, or as a replacement for, other mechanisms involving high pore water pressures, rock melting or high-pressure metamorphosis.

\section{ACKNOWLEDGEMENTS}

This research was supported by the New Zealand Foundation for Research, Science and Technology, through the Public Good Science Fund. We thank Rick Diehl for designing and constructing the rheometer, and Mike Evans for assisting with experimental work. Ze'ev Reches drew our attention to the need to consider the grain comminution rate.

\section{REFERENCES CITED}

Aharonov, E. and Sparks, D. (2006), Shear profiles and localisation in simulations of granular materials. Physical Review E v 65, 051302 1-12.

Anders, M.H, Aharonov, E. and Walsh, J.J. (2000) Stratified granular media beneath large slide blocks; implications for mode of emplacement. Geology, v 28, p 971-974.

Anthony J.L. and Marone, C. (2005), Influence of particle characteristics on granular friction. Journal of Geophysical Research v 110, B08409 Doi: 10.1029/2004JB003399.

Battacharya, S., S.P.G. Madabhushi, and M.D. Bolton (2004) An alternative mechanism of pile failure in liquefiable deposits during earthquakes. Géotechnique v 54, 203-213.

Beeler, N.M., Tullis, T.E., Blanpied, M.L. and Weeks, J.D. (1996), Frictional behaviour of large displacement faults. Journal of Geophysical Research v 101 p 8697-8715.

Bergstrom, C H. 1963. Energy and size distribution aspects of single particle crushing. In: Fairhurst, C. (Ed) Rock Mechanics, Proceedings of the $5^{\text {th }}$ Symposium on Rock Mechanics, May 1962. Pergamon Press, New York, p 155-172.

Benz, W. and Ausphaug, E. (1995), Simulations of brittle solids using smooth particle hydrodynamics. Computer Phys. Comm. v 87, p 253-26.

Beutner, E.C., and Gerbi, G.P. , 2006. Catastrophic emplacement of the Heart Mountain blockslide, Wyoming and Montana, USA. GSA Bulletin, 117:; 724-735; doi: 10.1130/B25451.1.

Biegel, R.L., Sammis, C.G. and Dieterich, J.H. (1989), Frictional properties of simulated debris. Journal of Structural Geology v 11, p 827-846.

Byerlee, J. (1978), Friction of rocks. Pure and Applied Geophysics v 116, 4-5, p 615-626.

Charles, R.J. (1957), Energy-size relationships in comminution. Mining Engineering, (Trans. AIME), p 80-88.

Davies, T.R.H and McSaveney, M.J. (2002), Dynamic simulation of the motion of fragmenting rock avalanches. Canadian Geotechnical Journal, v 39, p 789-798.

Davies, T.R., Deganutti, A.M. \& McSaveney, M.J. (2005), A high-stress rheometer for fragmenting rock. In: Picarelli,L. (ed.) Proceedings, international conference on fast slope movements. Naples, May 11-13, 1. Patron Editore, Bologna, p 139-141.

Davies, T.R., McSaveney, M.J. and Beetham, R. (2006), Rapid block glides - slide-surface fragmentation in New Zealand's Waikaremoana landslide. Quarterly Journal of Engineering Geology and Hydrogeology v 39, p 115-129.

Di Toro, G., Goldsby, G.L. and Tullis, T.E. (2004), Friction falls towards zero in quartz rock as slip velocity approaches seismic rates. Nature, v 227, p 436-430.

Dunning, S.A. 2004. Rock avalanches in high mountains - A sedimentological approach. $\mathrm{PhD}$

Thesis. University of Luton, U.K.

Espinoza H.D. and Xu, Y. (1997), Micromechanics of failure waves in glass 1, experiments. Journal of the American Ceramics Society v 80, p 2061-2073.

François, B., Lancombe, F. and Hermann, H.J. (2002), Finite width shear zones. Physical Review E v 65, 031311 1-7.

Freed, A.M. and Lin, J. (2002), Accelerated stress buildup on the southern San Andreas fault 
and surrounding regions caused by Mojave Desert earthquakes. Geology v 30, p 571-574.

Goldsby, D.L. and Tullis, T.E. (2002), Low frictional strength of quartz rocks at subseismic slip rates. Geophysical Research Letters v 29, p 1844.

Scholz, C.H. (2002).The Mechanics of Earthquakes and Faulting. Cambridge UP, $2^{\text {nd }}$ Ed., 469 p.

Grady, D.E. and Kipp M.E. (1987), Dynamic rock fragmentation. In: Fracture Mechanics of Rock, Academic Press, London, UK, p 429-475.

Hauge, T.A. 1990. Kinematic model of a continuous Heart Mountain allocthon. GSA Bulletin, 102:1174-1188; doi:10.1130/00167606(1990) 1022.3. CO;2.

Hazzard, J.F. and Mair, K. (2003), The importance of the third dimension in granular shear. Geophysical Research Letters v 30 doi: 10.1029/ 2003GL017534

Hazzard, J.F., Young, R.P and Maxwell, S.C. (2000) Micromechanical modeling of cracking and failure in brittle rocks. Journal of Geophysical Research v 105 p 16638-16697.

Herget, G. (1988), Stresses in Rock. Balkema, Rotterdam. 179 p.

Kilgore, B.D., Blanpied, M.L. and Dieterich, J.H. (1993), Velocity dependent friction of granite over a wide range of conditions. Geophysical Research Letters v 20, p 903-906.

King, G.C.P. and C.G. Sammis (1992) The mechanism of finite brittle strain. Pure and Applied Geophysics v 138, 611 - 640

Kuhn, M.R. (1999) Structured deformation in granular materials. Mechanics of Materials, v 31, p 407-429.

Lachenbruch, A.H. (1980), Frictional heating, fluid pressure and the resistance to fault motion. Journal of Geophysical Research v 85, p 62496272.

Li, X.B., Lok, T.S. and Zhao, J. (2005) Dynamic characteristics of granite subjected to intermediate loading rate. Rock Mechanics and Rock Engineering, v 38 p 21-39.

Mair, K., Frye, K.M. and Marone, C. (2001), Influence of grain characteristics on the friction of granular shear zones. Journal of Geophysical Research v 107, p 2219, Doi:10.1029/2001 BJ000516.

Marone, C. (1998), The effect of loading rate on static friction and the rate of fault healing during the earthquake cycle. Nature v 391, p 69-72.

Marone, C. and Kilgore, B. (1993), Scaling of the critical slip distance for seismic faulting with shear strain in fault zones. Nature v 362, p 618-621.

Melosh, H.J., Ryan, E.V. and Ausphaug, E. (1992), Dynamic fragmentation in impactsp hydrocode simulation of laboratory impacts. Journal of Geophysical Research v 97, p 14,735-14,759.

Morrow, C.A. and Byerlee, J.D. (1989), Ex- perimental studies of compaction and dilatancy during frictional sliding on faults containing gouge. Journal of Structural Geology v 11, p 815-825.

Parsons, T. (2002), Nearly frictionless faulting by unclamping in long-term interaction models. Geology v 30, p 1063-1066.

Reches, Z. and Dewers, T.A. (2005), Debris formation by dynamic pulverization during earthquake rupture. Earth and Planetary Science Letters v 235, p 361-374.

Sagy, A., Reches, Z. and Roman, I. (2001), Dynamic fracturing field and experimental observations. Journal of Structural Geology, v 23, p 12231239.

Scholz, C.H. The Mechanics of Earthquakes

and Faulting. Cambridge UP, $2^{\text {nd }}$ Edn., $469 \mathrm{p}$

Sharpton, V.L., Dressler, B.O., Herrick, R.R., Schneiders, B. and Scott, J. (1996), New constraints on the Slate Islands impact structure, Ontario, Canada. Geology v 24 p 851-854.

Sibson, R.H. (1994), An assessment of field evidence for "Byerlee" friction. Pure and Applied Geophysics v 142, p 645-662.

Sibson, R. (2003), Thickness of seismic slip zone. Bulletin, Seismological Society of America v 93, p1169-1178, DOI: 10.1785/012002 0061.

Tarantino, A. and Hyde, A.F.L. (2005), An experimental investigation of work dissipation in crushable materials. Géotechnique v 55, p 575-584.

Toakley, A.R. (1965) Buckling loads for elastically supported struts. Journal of the Engineering Mechanics Division, ASCE, v 91, p 205-231

Townend, J., and Zoback, M. D (2004), Regional tectonic stress near the San Andreas fault in central and southern California. Geophysical Research Letters v 31, L15S11, doi:10.1029/2003 GL018918

Wawersik, W.F. and Fairhurst, C. (1971); A study of brittle rock fracture in laboratory compression experiments. International Journal of Rock Mechanics and Mining Sciences. v 7 p 561-575.

Zhang, Z.H., Kou, S.Q., Liang, L.G. and Lindqvist, P.-A. (2000), Effects of loading rate on rock fracture: fracture characteristics and energy partitioning. International Journal of Rock Mechanics and Mining Science v 37, p 745-762.

Zhang, Y.-Q., Lu, Y. and Hao, H. (2004). Analysis of fragment size and ejection velocity at high strain rate. International Journal of Mechanical Sciences v 46, p 27-34. 